\title{
Game of the radicals: Intervention in teaching simplifying
} radicals

\author{
Alvarez, Joel I. \\ College of Education, Nueva Ecija University of Science and Technology, Philippines \\ (Alvarezjoel.641ryu@gmail.com)
}

Received: 16 April 2020

Available Online: 24 January 2021

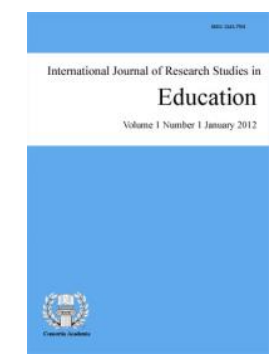

ISSN: 2243-7703 Online ISSN: 2243-7711

OPEN ACCESS

\section{Abstract}

According to Cerulli and Mariotti (2014), developing students' knowledge in transforming or simplifying radical expressions poses a significant challenge for teachers. The mastery of the said skill is needed on the proceeding topics on Grade 9 Mathematics such as the operations involving radical expressions. This study aimed at testing the effectiveness of integrating a game based learning in the form of a game board called Game of the Radicals in teaching simplifying radicals. It described the performance of group of students in simplifying radicals before and after a series of playing the Game of the Radicals using pre-test and post-test design and test whether there is significant difference between the pre-test and post-test scores of the subjects under study. This study was conducted to selected Grade 9 (15) students of College of the Immaculate Conception during the A.Y 2019-2020. The study used the pretest-posttest experimental design of research. This study utilized T-test for dependent sample to test whether there is a significant difference between the pre-test and post-test scores of the groups. Results showed that, it made enough statistical evidence to have concluded that There is a significant difference in the problem solving skills of subjects in the pre-test and post-test of the group of subjects. Thus, this result implies that using Game of the Radicals in teaching simplifying radicals is a great tool to master the said competency. Also, curriculum developers may consider integrating the use of modified board games in teaching Mathematics.

Keywords: experimental; intervention; mathematical proficiency; problem solving skills; radicals 


\section{Game of the radicals: Intervention in teaching simplifying radicals}

\section{Introduction}

According to Cerulli et al. (2014), developing students' knowledge in transforming or simplifying radical expressions poses a significant challenge for teachers. Students struggle with simplifying radical expressions are shown by researches. Simplifying radical expressions is an essential skill among the students. The mastery of the said skill is needed on the proceeding topics on Grade 9 Mathematics such as the operations involving radical expressions. Based on the statistical results of the examinations conducted by the researcher among his students, it was shown that simplifying radical expressions is one of the least learned skills of the students during the 2 nd Quarter. With this, it resulted to students' difficulty involving operations of radical expressions since the main skill needed in these competencies is simplifying radical expressions.

The serious question that arises then is what a mathematics teacher can do to stir such interest and motivation and higher order thinking skills in students to learn. In an effort to engage children in Mathematics learning, many teachers use Mathematical games. The idea of using games to engage learners in the process of active learning is not new. As cited by Cicchino (2015), Game-Based Learning environment enables learners to make meaningful choices within problem (McCall, 2011) and often present learner with ill-structured problems, well-structured rules with ill-structured paths to resolution, students typically work in small groups and construct knowledge through the activation of prior understanding, as well as by engaging in collaborative discourse (Gresalfi et al., 2009; Hmelo-Silver et al., 2008).

Game-Based Learning intervention were effective in promoting higher level of critical thinking including the development of independent beliefs prior to engaging in collaborative discourse and providing opportunities for guided reflection (Cicchino, 2015). Thus, this paper focused in constructing a game which may enhance the simplifying skills and evaluating the effectiveness of board game in learning simplifying radicals.

\section{Theoretical framework}

Although there are many different approaches to learning, there are three basic types of learning theory: behaviorist, cognitive constructivist, and social constructivist. View of learning in behaviorism, passive absorption of a predefined body of knowledge by the learner. Promoted by repetition and positive reinforcement; the cognitive constructivism, active assimilation and accommodation of new information to existing cognitive structures. Discovery by learners, social constructivism, and the integration of students into a knowledge community, which includes the collaborative assimilation and accommodation of new information.

This study created the board game as an intervention to test whether there is significant difference between the performances of students in simplifying radical expressions before and after the series of playing the constructed board game, Game of the Radicals.

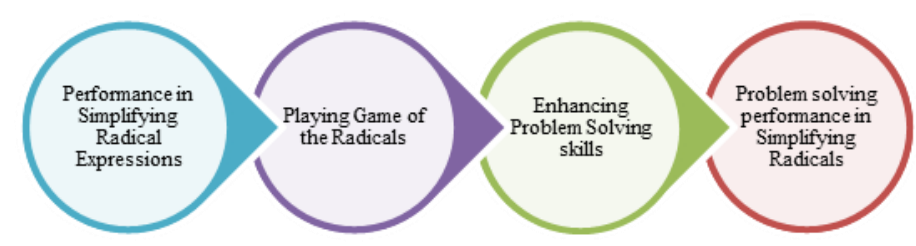

Figure 1. Research paradigm. 
This figure shows the research paradigm of the study. The paradigm starts with diagnosing the level of performance of the subjects in simplifying radical expressions. The subjects are then classified according to the result of their performance test involving radical expressions. After diagnosing the level of their performance, the subjects are then subjected to the intervention which is the series of playing of Game of the Radicals that may enhance the problem solving skills of the students. After the series of playing Game of the Radicals, a post-test was given. The utility of the created board game, Game of the Radicals will be used as a treatment. The said pre-test and post-test was used to determine whether there was a significant difference in the performance of the students before and after playing the game.

\subsection{Statement of the problem}

Generally, this study aims to investigate the effectiveness of game intervention through the use of Game of the Radicals. Specifically, the study aims to answer the following:

1. How may the performance of the students in simplifying radical expressions be described: before a series of playing Game of the Radicals; and after a series of playing Game of the Radicals?

2. Is there significant difference in the performance of the students in simplifying radical expressions before and after a series of playing Game of the Radicals?

\subsection{Hypothesis of the study}

There is no significant difference in the performance of the students in simplifying radical expressions before and after a series of playing Game of the Radicals.

\subsection{Significance of the study}

This study may serve as a guide for the development of a curriculum anchored on the needs of the students in mathematics instruction to create better curricula that will promote better learning. It can serve as a guiding tool and basis of instruction to improve their teaching strategy in the field of mathematics. It may serves as a reflection that they can have different ways to learn the topic simplifying radical expressions. This study may serve as a basis of future studies. These researchers may study the other disciplines of mathematics. It is a source of review of related literature.

\section{Research methodology}

This portion presents the research method, sampling technique, participants of the study, instrumentation and validation, procedures of the study, and data analysis.

\subsection{Method}

The experimental research design was used in this study. Experimental design of research represents the most valid approach to the solution of educational problems, both practical and theoretical, and to the advancement of education as a science (Gay, 1992). This used one group pre-test-post-test experimental design (Cohen et al., 2007). One group pre-test/post-test control design is an experiment where measurements are taken both before and after a treatment. The design means that you are able to see the effects of some type of treatment on a group. This is widely used in behavioral research primarily in measuring change resulting from experimental treatment. 
This study used experimental design of research. A board game version of Mobile Legends: the Game of the Radicals used the following diagram fundamentally described the design of the study:

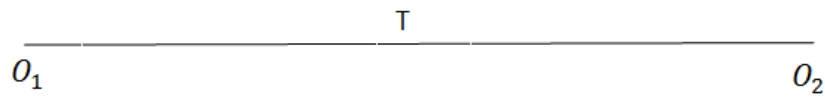

$$
\begin{aligned}
& \text { Where: } \\
& \mathrm{O}_{1} \text {-pretest } \\
& \mathrm{O}_{2} \text { - posttest } \\
& \mathrm{T} \text { - intervention/treatment }
\end{aligned}
$$

Figure 2. The research design.

\subsection{Research locale}

This study was conducted at the College of the Immaculate Concepcion which is located at Sumacab Este, Cabanatuan City, Nueva Ecija with more than 280 Grade 9 students.

\subsection{Sampling technique}

This study will use purposive type of sampling technique. Purposive is a non-probability sampling that select the samples based on a certain criteria laid down by the researchers. In this study, the researcher selected the samples based on their 2nd Quarter grade on mathematics 9.

\subsection{Participants of the study}

This study will be conducted to Grade 9 students from College of the Immaculate Concepcion. Participants consist of fifteen (15) Grade 9 students from College of the Immaculate Concepcion purposely selected from different sections considering their 2nd quarterly grade on mathematics 9 .

\subsection{Research instruments and validation}

This study made use of instruments that was of help to obtain the data and for the success of the study. The instrument had been prepared through the help and guidance of the researcher' consultants. This study used i.) Game of the Radicals: A Strategic Intervention Material in Simplifying Radical Expressions, and ii.) Teacher Made Test, the Problem Solving Test in Simplifying Radical Expressions.

\section{i. Game of the radicals: A strategic intervention material in simplifying radical expressions}

Description. Game of the Radicals is a strategic intervention material designed to help the students gain mastery on simplifying radical expressions which is one of the least learned skills in Mathematics 9 during the second quarter of the school year 2018-2019. This strategic intervention material is based on the famous board game among teenagers which is the Game of the Generals. Unlike the usual strategic intervention materials, Game of the Radicals is a game-based one to make the reinforcement of the focus skill more interactive and appealing to students. This is like the usual Game of the Generals with twists and the aesthetic of Mathematics. Their goal is to reach the Victory which is located on the flag tile of the game board. All throughout the game, the students will have three activities, each with increasing difficulty. The first activity is move a pawn of their choice. Each tile where the pawn will land had a radical expression. For the player to successfully land on that tile, he/she must simplify the given radical expression. Upon giving correct answer, the students can now move their pawn. If their pawn land on a tile where there is another pawn of the competing side, they have to draw from the deck of Pawn Cards. Each card contains a problem about simplifying radical expressions. If they got the correct answer first, they will advance to the tile where they land and oppose the other team otherwise, their

76 Consortia Academia Publishing (A partner of Network of Professional Researchers and Educators) 
Game of the radicals: Intervention in teaching simplifying radicals

pawn will be eliminated from the game. The third activity happens when their reach the flag tile. To advance to this tile and win the game, they have to challenge the opposing team in a clash by drawing a Flag Card which contains another problem on simplifying radical expressions.

Validation. The draft questions used in the board game was checked by an expert in the field of Mathematics and was pilot-tested to a group of Grade 10 students who have taken Grade 9 mathematics and were not members of the sample. After the pilot-testing and analyzing the internal consistency, the 60 item test later became 50 with an alpha index of .718 .

\section{ii. Problem Solving Test in Simplifying Radical Expressions}

Description. Problem Solving Test in Simplifying Radical Expressions (PSTSRA) is a teacher-made test which contains items involving simplifying radical expressions content of Grade 9 Mathematics under the $\mathrm{K}$ to 12 curriculum. It is multiple choice type of test that contains 50 items with four (4) choices each. A Table of Specification of PSTSRA was prepared for this purpose.

Validation. The draft form of PSTSRA was checked by an expert in the field of Mathematics and was pilot-tested to a group of Grade 10 students who have taken Grade 9 mathematics and were not members of the sample. After the pilot-testing and analyzing the internal consistency, the 60 item test later became 50 with an alpha index of .713.

Scoring. One point was allotted to every correct answer with correct solution or explanation given by the student. Correct letter of choice which requires solution and had no solution was given no point.

\subsection{Procedures of the study}

The researcher conducted this study through the following:

Asking Permission. The researcher secured a permission to conduct from the Principal of the participating school to allow their students be a participant during the validation of the instruments and for the conduct of the study for a period of 1 month.

Instrument Preparation and Validation. The instrument had been prepared and validated through the help and guidance of the researcher's consultants. This study used a board game entitled "Game of the Radicals", and Problem Solving Test in Simplifying Radical Expressions. The researcher consulted experts for the validation of each instrument. The examination was pilot tested a group of Grade 10 students who already took Grade 9 Mathematics and were not members of the subjects under study. The Pilot testing lasted for 3 days.

Administration of the Pre-test. Administration of pre-test was done to the subjects of this study. Prior directions were given.

Series of Playing the Board Game: Game of the Radicals. The researcher conducted this study using the board game: Game of the Radicals constructed and prepared for the purpose of assessing the "Intervention of Playing Game of the Radicals in Teaching Simplifying Radical Expressions", for a period of 5 hours equivalent to 5 meetings in the research locale.

Administration of the Post-test. Post-test was administered a day after the series of playing the board game: Game of the Radicals.

\subsection{Data analysis}

In this study, the data gathered will be analyzed using the following statistical treatment.

$>$ To describe students' performance in solving problems in simplifying radical expressions before and 
after a series of playing Game of the Radicals, mean will be used and interpreted using the following interval.

$$
\begin{gathered}
\text { Interval } \\
40.01-50.0 \\
30.01-40.0 \\
20.01-30.0 \\
10.01-20.0 \\
0.0-10.0
\end{gathered}
$$

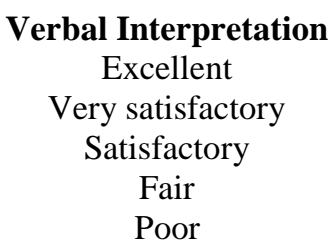

$>$ To test the significant difference in the performance before and after a series of playing Game of the Radicals, t-test for dependent sample was used.

\section{Results and discussion}

Performances of the subjects in simplifying radical expressions.

\subsection{Before the series of playing Game of the Radicals}

Table 1 shows the problem solving skills of the students before the intervention. Based on the table, it shows that in a 50 item test given before a series of intervention, student 4 scored 35, student 5 obtained a score of 32 and student 7 scored 34 and were all rated as very satisfactory. On the other hand, student 1 scored 24 and student 8 scored 21, both rated as satisfactory. Lastly, student 2 scored 16, student 3 and 9 scored 20, student 6 scored 12, student 10 scored 15 and were all rated as fair. The group obtained a mean score of 22.90 and were interpreted to perform satisfactory.

\section{Table 1}

Scores in PSTSRA before the intervention

\begin{tabular}{ccc}
\hline Subject & Score in PSTSRA & Verbal Interpretation \\
\hline 1 & 24 & Satisfactory \\
2 & 16 & Fair \\
3 & 20 & Fair \\
4 & 35 & Very Satisfactory \\
5 & 32 & Very Satisfactory \\
6 & 12 & Fair \\
7 & 34 & Very Satisfactory \\
8 & 21 & Satisfactory \\
9 & 20 & Fair \\
10 & 15 & Fair \\
Mean Score & 22.90 & Satisfactory \\
\hline
\end{tabular}

The table reveals that subjects in the group performed satisfactorily in simplifying radicals before the series of playing Game of the Radicals. Since there are students who are below satisfactory performance in simplifying radical, it can be implied that there is a need for intervention of playing Game of the Radicals to enhance their performance.

\subsection{After the series of playing Game of the Radicals}

Table 2 shows the problem solving skills of the students after the intervention. Based on the table, it shows that in a 50 item test given after a series of intervention, student 4 scored 43 , student 5 obtained a score of 44 and student 7 scored 48 and were all rated as excellent. On the other hand, student 1 scored 32, student 3 got 35, student scored 32 and student 9 scored 31, both rated as very satisfactory. Lastly, student 2 scored 25, student 6 scored 23, and student 10 scored 28 and were all rated as satisfactory. The group obtained a mean score of 34.10 and were interpreted to perform very satisfactory. 
Table 2

Scores in PSTSRA after the intervention

\begin{tabular}{ccc}
\hline Subject & Score in PSTSRA & Verbal Interpretation \\
\hline 1 & 32 & Very Satisfactory \\
2 & 25 & Satisfactory \\
3 & 35 & Very Satisfactory \\
4 & 43 & Excellent \\
5 & 44 & Excellent \\
6 & 23 & Satisfactory \\
7 & 48 & Excellent \\
8 & 32 & Very Satisfactory \\
9 & 31 & Very Satisfactory \\
10 & 28 & Satisfactory \\
Mean Score & 34.10 & Very Satisfactory \\
\hline
\end{tabular}

The table reveals that subjects in the group performed very satisfactorily in simplifying radicals after the series of playing Game of the Radicals. When compared to the result of the problem solving skills of the subjects before the instruction, it is eminent that all the subjects have consistently improved their scores after the series of playing of Game of the Radicals. It shows that the subjects in general got an overall mean score of 34.10 with a verbal interpretation of very satisfactory. During the post-test, it was observed that all of the subjects under the group was focused and silently answered the examination. None of them frowned while answering or even bothered asking their facilitator about some points in the test. Based on the result of the table and observations, it can be deduced that the subjects under the group have obtained an improvement in terms of their problem solving skills in simplifying radicals.

\subsection{Paired sample T-test for the performance before and after the series of playing Game of the Radicals}

The t-test result and the significant difference in the scores of the subjects before and after a series of intervention with mean difference of -11.20 and standard deviation of 2.39. The computed sig of .000 is less than the sig critical value of .05 . Hence, there is enough statistical evidence to reject the null hypothesis that there is no significant difference in the performance of the students in simplifying radical expressions before and after a series of playing Game of the Radicals at 5\% level of significance. It is therefore concluded that there is a significant difference in the performance of the students in simplifying radical expressions before and after a series of playing Game of the Radicals. This implies that the subjects under study have positively improved their skill of simplifying radicals after playing the intervention material "Game of the Radicals".

\section{Conclusions}

Based on the findings of this study, the following conclusions were drawn.

$>\quad$ The students under the study performed satisfactorily in simplifying radicals before a series of playing Game of the Radicals and very satisfactorily after a series of playing Game of the Radicals.

$>\quad$ There is a significant difference in the performance of the students in simplifying radical expressions before and after a series of playing Game of the Radicals. The mean score of the pre-test of the group increase after the series of intervention.

$>\quad$ There is a significant difference in the problem solving skills of the students under study after they played the intervention material "Game of the Radicals".

$>\quad$ In this study, using of Game of the Radicals as a strategic intervention material in simplifying radicals is considered effective. 


\subsection{Recommendations}

Based on the findings and conclusion of this study, the following recommendations were formulated:

$>$ Teachers of Algebra may look into the possibility of using Game of the Radicals in teaching simplifying radicals and problem solving skills in their content courses.

$>$ Similar studies may be conducted using students in other school to further determine the effectiveness of using the intervention material.

$>$ Curriculum developers may consider integrating board games in their curriculum.

$>$ This study was conducted in a smaller group of subjects. With this, the researcher highly recommended that this study be conducted in a larger group to see if there is a consistency of result.

$>$ Studies on the use of modified board games in teaching different branch of mathematics be conducted in both quantitative and qualitative.

\section{References}

Cerulli, M., Pedemonte, B., \& Robotti, E. (2014). An integrated perspective to approach technology in mathematics education. In M. Bosh (Ed.), Proceedings of CERME 4 (pp. 1389-1399). IQS Fundemi Business Institute.

Cicchino, M. I. (2015). Using game based learning to foster critical thinking in student discourse. Interdisciplinary Journal of Problem Based Learning, 9(2). https://doi.org/10.7771/1541-5015.1481

Cohen, L., Manion, L., \& Morrison, K. (2007). Research method in education (6th ed.). Routledge. https://doi.org/10.4324/9780203029053

Gay, L. R. (1992). Education research competencies for analysis and application (4th ed.). New York, NY: Merrill.

Gresalfi, M., Martin, T., Hand, V. M., \& Greeno, J. (2009). Constructing competence: An analysis of student participation in the activity systems of mathematics classrooms. Educational Studies in Mathematics, 70(1), 49-70. https://doi.org/10.1007/s10649-008-9141-5

Hmelo-Silver, C. E., Chemobilsky, E., \& Jordan, R. C. (2008). Understanding collaborative learning processes in new learning environments. Instructional Science, 36(5), 409-430.

https://doi.org/10.1007/s11251-008-9063-8

McCall, J. (2011). Gaming the past: Using video games to teach secondary history. New York, NY: Routledge. 